\title{
Correction to: Imaging of fetal brain tumors
}

\author{
Patricia Cornejo ${ }^{1,2,3,4,5} \cdot$ Tamara Feygin $^{6}$ - Jennifer Vaughn ${ }^{1,2,3,5}$. Cory M. Pfeifer ${ }^{7}$ - Alexandra Korostyshevskaya ${ }^{8}$. \\ Mittun Patel $^{1,3,5} \cdot$ Dianna M. E. Bardo ${ }^{1,2,3,4,5} \cdot$ Jeffrey Miller ${ }^{1,2,3,4,5} \cdot$ Luis F. Goncalves $^{1,3,5}$
}

Published online: 12 January 2021

(C) Springer-Verlag GmbH Germany, part of Springer Nature 2021

\section{Correction to: Pediatric Radiology (2020) 50:1959-1973 https://doi.org/10.1007/s00247-020-04777-z}

Originally, this article was published with an incorrect author name. The correct name is Alexandra Korostyshevskaya, as presented above, instead of Alexandra Korostyshevska.

Publisher's note Springer Nature remains neutral with regard to jurisdictional claims in published maps and institutional affiliations.

The online version of the original article can be found at https://doi.org/ 10.1007/s00247-020-04777-z

Patricia Cornejo

pcornejo@phoenixchildrens.com

1 Department of Radiology, Phoenix Children's Hospital, 1919 E. Thomas Road, Phoenix, AZ 85016, USA

2 Department of Neuroradiology, Barrows Neurological Institute, Phoenix, AZ, USA

3 Department of Radiology, University of Arizona College of Medicine, Phoenix, AZ, USA

4 Department of Radiology, Mayo Clinic Arizona, Phoenix, AZ, USA

5 Department of Radiology, Creighton University School of Medicine, Phoenix, AZ, USA

6 Department of Radiology, The Children's Hospital of Philadelphia, Philadelphia, PA, USA

7 Department of Radiology, UT Southwestern, Dallas, TX, USA

8 International Tomography Center of the Siberian Branch of the Russian Academy of Sciences, Novosibirsk, Russian Federation 